\title{
Cardiovascular responses to microinjection of trans-( \pm )-ACPD into the NTS were similar in conscious and chloralose-anesthetized rats
}

B.H. Machado and L.G.H. Bonagamba
Departamento de Fisiologia, Faculdade de Medicina de Ribeirão Preto, Universidade de São Paulo, Ribeirão Preto, SP, Brasil

\section{Correspondence \\ B.H. Machado \\ Departamento de Fisiologia FMRP, USP \\ Av. Bandeirantes, 3900 14049-900 Ribeirão Preto, SP Brasil \\ Fax: 55 (016) 633-0017 \\ E-mail:bhmachad@fmrp.usp.br \\ Research supported by FAPESP, CNPq and PRONEX.}

Received June 4, 1997 Accepted January 14, 1998

\section{Abstract}

The changes in mean arterial pressure (MAP) and heart rate (HR) in response to the activation of metabotropic receptors in the nucleus tractus solitarii (NTS) with trans-( \pm )-1-amino-1,3-cyclopentanedicarboxylic acid (trans- $( \pm$ )-ACPD) were evaluated in conscious and anesthetized Wistar, male rats weighing 240-260 $\mathrm{g}(\mathrm{N}=8)$. The responses obtained with trans- $( \pm)$-ACPD were compared with the responses to L-glutamate $(1 \mathrm{nmol} / 100 \mathrm{nl})$, since in a previous study we showed that anesthesia converted a pressor response to L-glutamate microinjected into the NTS of conscious rats to a depressor response in the same rats under urethane or chloralose anesthesia. Microinjection of 3 doses of trans-( \pm )-ACPD $(100,500$ and $1000 \mathrm{pmol} / 100 \mathrm{nl})$ produced a dosedependent fall in MAP (range, -20 to $-50 \mathrm{mmHg}$ ) and HR (range, -30 to $-170 \mathrm{bpm}$ ) under both conscious and chloralose anesthesia conditions. These data indicate that the cardiovascular responses to the activation of metabotropic receptors by trans-( \pm -ACPD are not affected by chloralose anesthesia while the cardiovascular responses to the activation of excitatory amino acid (EAA) receptors by L-glutamate are significantly altered.

\section{Introduction}

The excitatory amino acid (EAA) L-glutamate is the most important candidate as a neurotransmitter of the baroreceptors afferents in the nucleus tractus solitarii (NTS) (13). L-Glutamate activates different subtypes of ionotropic receptors (NMDA, kainic and AMPA/quisqualate) in the NTS and recent studies have indicated the presence of kynurenic-insensitive EAA receptors related to the metabotropic class of receptors in the NTS $(2,4,5)$. The specific role of each of these different classes of receptors in the
Key words

- Trans-( \pm -ACPD

- L-glutamate

- Ionotropic receptors

- Excitatory amino acid receptors

- Neurotransmission

- Baroreflex

- Chloralose anesthesia

- Trans-( \pm )-1-amino-1,3cyclopentanedicarboxylic acid neurotransmission of baroreceptor afferents in the NTS, and their involvement in the modulation of postsynaptic neurons related to the sympathetic and parasympathetic branches of the baroreflex are not fully understood.

Microinjection of L-glutamate into the commissural NTS of conscious freely moving rats, in contrast to anesthetized animals, produces an increase in arterial pressure and bradycardia (6-8). These cardiovascular responses to L-glutamate are due to a nonselective activation of different subtypes of ionotropic receptors, considering that these 
responses were blocked in a dose-dependent manner by kynurenic acid previously microinjected into the NTS (6). On the other hand, since L-glutamate microinjected into the NTS of conscious rats produces an increase in arterial pressure, while under anesthesia it produces a fall in pressure, we may suggest that anesthesia plays a critical role in the generation of this opposite response. In the present study we evaluated the cardiovascular effects of microinjection of trans-( \pm )-1amino-1,3-cyclopentanedicarboxylic acid (trans-( \pm )-ACPD), a metabotropic agonist, into the commissural NTS of conscious rats and also in the same animals under chloralose anesthesia. The cardiovascular changes produced by trans-( \pm )-ACPD were compared with the responses produced by L-glutamate in order to determine the pattern of cardiovascular responses produced by activation of metabotropic receptors and also to determine whether these responses are affected by the anesthetic.

\section{Material and Methods}

Male Wistar rats weighing 240-260 g were used in the experiments. Four days before the experiments rats under tribromoethanol anesthesia (Aldrich, 2.5\%, $1 \mathrm{ml} / 100$ $\mathrm{g}$, ip ) were placed in a stereotaxic apparatus (David Kopf, Tujunga, CA) and a unilateral guide cannula for microinjections into the NTS was fixed to the skull in accordance with the coordinates of the atlas of Paxinos and Watson (9) and the technique described by Michelini and Bonagamba (10). The needle (33 gauge) used for the micronjections was $1.5 \mathrm{~mm}$ longer than the guide cannula and was connected to a $1-\mu l$ syringe (Hamilton) by PE-10 tubing. The needles for microinjection were inserted into the guide cannula and the injection was initiated $15 \mathrm{~s}$ later. After each microinjection the needles were removed and washed with saline before being loaded with the next dose to be microinjected. Microinjections into the NTS were performed in a volume of $100 \mathrm{nl}$ and all solutions were freshly dissolved in saline, with the $\mathrm{pH}$ adjusted to 7.0.

One day before the experiments, under ether anesthesia, a catheter was inserted into the abdominal aorta through the femoral artery for measurement of pulsatile arterial pressure (PAP), mean arterial pressure (MAP) and heart rate (HR) and a second catheter was introduced into the femoral vein for anesthetic administration. Both catheters were tunneled and exteriorized through the back of the neck to be used under conscious conditions. After the initial sequence of microinjections into the NTS under conscious conditions, the rats were anesthetized with $\alpha$-chloralose (Sigma Chemical Co., St. Louis, MO; $50 \mathrm{mg} / \mathrm{kg}, i v$ ) and the microinjections of L-glutamate and different doses of trans( \pm )-ACPD (RBI, Natick, MA) into the NTS were repeated in a random sequence $1 \mathrm{~h}$ after anesthesia. During the experiments under chloralose anesthesia, body temperature was kept at $37^{\circ} \mathrm{C}$ with a thermocontroller system (Department of Physiology Electronics Facility, School of Medicine of Ribeirão Preto, USP).

The microinjections of increasing doses of trans- $( \pm)-A C P D(100,500$ and $1000 \mathrm{pmol} /$ $100 \mathrm{nl}$ ) into the NTS of conscious or anesthetized rats were performed in a random sequence at minimal time intervals of 10 min. All conscious and anesthetized rats were microinjected with $100 \mathrm{nl}$ saline as a volume control prior to the activation of metabotropic receptors with trans-( \pm )-ACPD (RBI). LGlutamate $(1 \mathrm{nmol} / 100 \mathrm{nl})$ was also microinjected into the NTS in order to produce a nonselective activation of excitatory amino acid receptors, and the cardiovascular responses under conscious and anesthetized conditions were compared with the responses produced by trans-ACPD microinjection. The cardiovascular effects of trans-( \pm )-ACPD microinjected into the NTS were effectively due to activation of metabotropic receptors because in a recent study from our labora- 
tory (11) we showed that the responses to trans-( \pm )-ACPD (250 pmol/100 nl) were blocked by $\alpha$-methyl-4-carboxyphenylglycine, $( \pm)-(\mathrm{MCPG},( \pm)-; 2,5 \mathrm{nmol} / 100 \mathrm{nl})$ (RBI), a metabotropic receptor antagonist.

After the experiments, under $\alpha$-chloralose anesthesia, Evan's blue was microinjected into the same site for histological analysis and the rats were killed by intracardiac perfusion with saline followed by $10 \%$ buffered formalin. The brains were removed and stored in buffered formalin for 2 days and serial coronal sections $(10 \mu \mathrm{m})$ were cut and stained by the Nissl method. Only the rats whose microinjection site was located in the commissural NTS $(0.5 \mathrm{~mm}$ lateral to the midline) at the rostral edge of the area postrema were considered in the present study. No changes in arterial pressure or heart rate were observed in rats with misplaced microinjections of trans-( \pm -ACPD and L-glutamate into the fourth ventricle, cerebellum or into areas adjacent to the NTS in the brainstem.
Statistical analysis for comparison of the dose-response curves of trans- $( \pm)$-ACPD (MAP and HR) of conscious and anesthetized rats was performed by analysis of variance (ANOVA) followed by the F-test for differences between groups. The differences between changes in MAP and HR in response to microinjection of L-glutamate and saline (vehicle) into the NTS of conscious and anesthetized rats were compared by the Student $t$-test and the level of significance was set at $\mathrm{P}<0.05$.

\section{Results}

Figure 1 presents tracings of a rat representative of the group in which the animals received microinjections of saline, L-glutamate and 3 doses of trans-( \pm -ACPD into the NTS under conscious conditions. The figure shows that L-glutamate $(1 \mathrm{nmol} / 100 \mathrm{nl})$ produced an increase in MAP and bradycardia while trans- $( \pm)$-ACPD at the doses of 500 and $1000 \mathrm{pmol} / 100 \mathrm{nl}$ produced hypotension and bradycardia.

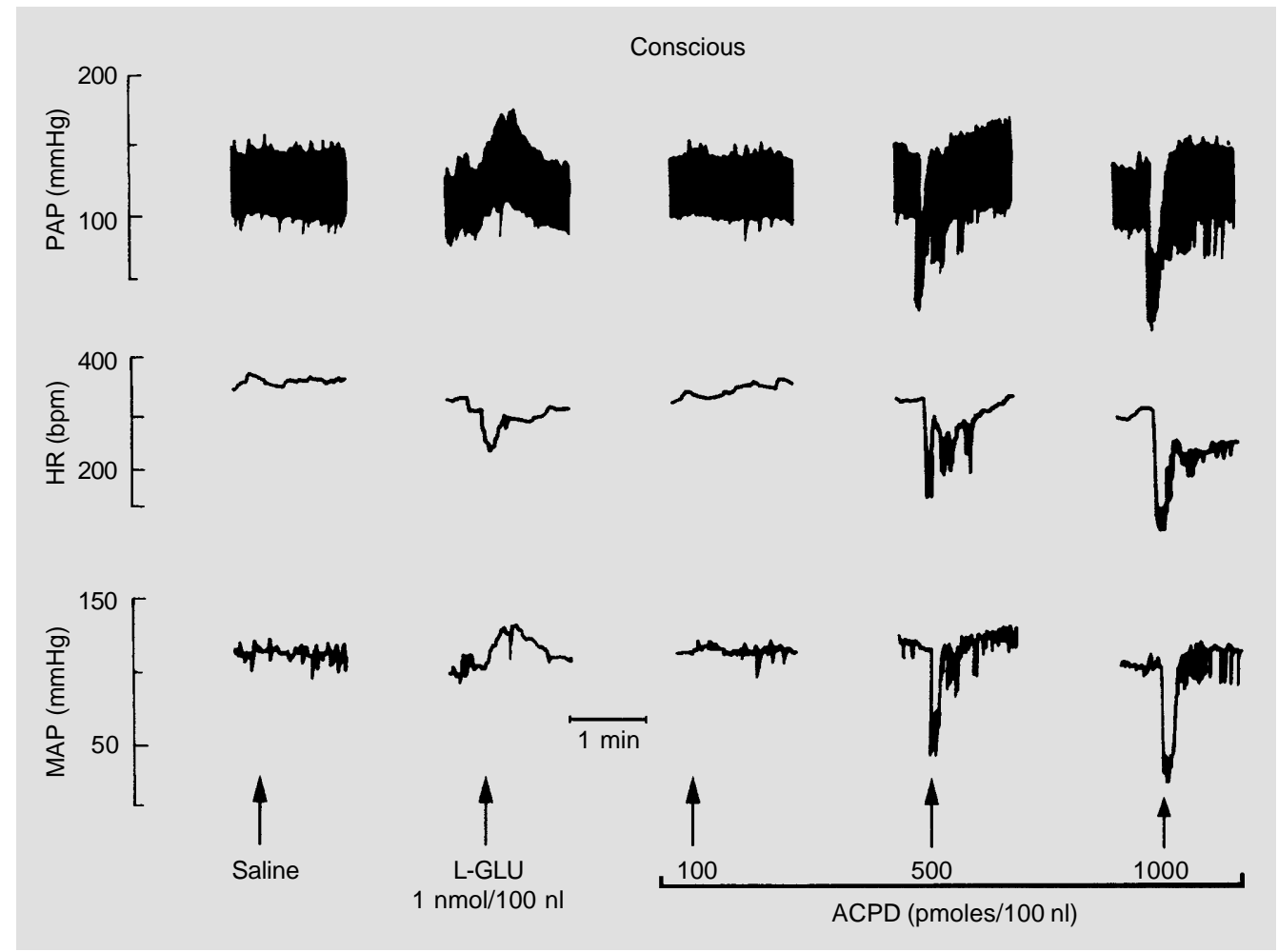

Figure 1 - Typical recordings of one rat representative of the group showing changes in pulsatile arterial pressure (PAP), heart rate $(\mathrm{HR})$ and mean arterial pressure (MAP) in response to microinjections of saline (100 nl), L-glutamate (L-GLU; $1 \mathrm{nmol} /$ $100 \mathrm{nl}$ ) and increasing doses of trans-( \pm )-1-amino-1,3-cyclopentanedicarboxylic acid (ACPD) into the NTS under conscious conditions. Arrows indicate microinjections into the NTS. Time interval between microinjections was $10 \mathrm{~min}$. 
Figure 2 presents a tracing of the same representative rat as used in Figure 1, now under chloralose anesthesia, which also received microinjections of saline, L-glutamate and 3 doses of trans-( \pm -ACPD into the NTS. Under anesthesia, L-glutamate produced hypotension and bradycardia while the cardiovascular responses to trans-( \pm ACPD were similar to those observed in conscious rats, i.e., hypotension and bradycardia.

Figure 3 summarizes the data obtained with trans-( \pm -ACPD under conscious and anesthetized conditions $(\mathrm{N}=8)$ and shows that trans- $( \pm)$-ACPD produced a similar dosedependent reduction in MAP and HR in both conscious and anesthetized animals. The hypotensive and bradycardic responses to each dose of trans-( \pm -ACPD after chloralose anesthesia were not statistically different in relation to the responses obtained under conscious conditions.

Figure 4 compares the data obtained with microinjection of L-glutamate and saline into the NTS of conscious and anesthetized rats. L-Glutamate produced an increase in MAP $(+28 \pm 5 \mathrm{mmHg})$ and bradycardia $(-135 \pm 24$ bpm) under conscious conditions and hypotension $(-24 \pm 7 \mathrm{mmHg})$ and bradycardia $(-40 \pm 8 \mathrm{bpm})$ under anesthesia. In addition to the opposite effect on MAP, anesthesia also produced a significant reduction in the bradycardic response to L-glutamate microinjection. Microinjection of saline (vehicle) into the NTS of conscious or anesthetized rats produced negligible effects on MAP and HR. Chloralose anesthesia produced no significant changes in baseline MAP (100 \pm 4 vs $94 \pm 4 \mathrm{mmHg})$ or HR $(377 \pm 17$ vs $345 \pm$ $11 \mathrm{bpm})$.

Figure 5 is a photomicrograph of a coronal section of the brainstem from a rat representative of the group in which the unilateral site of microinjection was located in the commissural NTS at the rostral edge of the area postrema, approximately $0.5 \mathrm{~mm}$ ros-
Figure 2 - Typical recordings of the same rat representative of the group presented in Figure 1 showing changes in pulsatile arterial pressure (PAP), heart rate (HR) and mean arterial pressure (MAP) in response to microinjections of saline (100 nl), L-glutamate (L-GLU; $1 \mathrm{nmol} / 100 \mathrm{nl}$ ) and increasing doses of trans-( \pm )-1amino-1,3-cyclopentanedicarboxylic acid (ACPD) into the NTS under anesthesia ( $\alpha$-chloralose, $50 \mathrm{mg} / \mathrm{kg}, i \mathrm{v}$ ). Arrows indicate microinjections into the NTS. The time interval between microinjections was $10 \mathrm{~min}$.

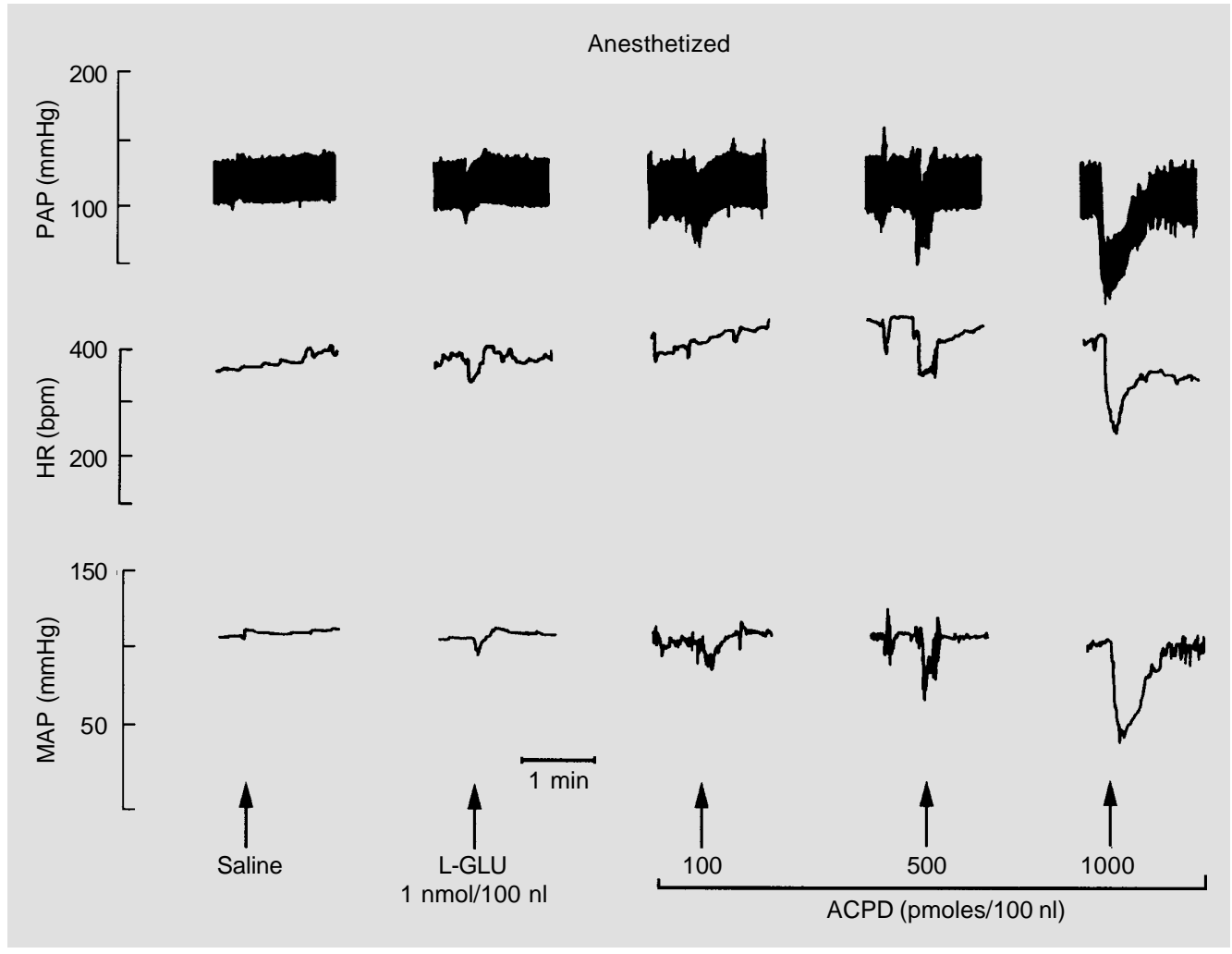


tral to the calamus scriptorius.

\section{Discussion}

The microinjection of trans- $( \pm)-\mathrm{ACPD}$ into the NTS of conscious and anesthetized rats produced similar dose-dependent hypotensive and bradycardic responses. The microinjection of L-glutamate into the NTS of the same rats under conscious and anesthetized conditions produced opposite effects on MAP, suggesting that receptors involved in the pressor response, probably of the ionotropic class, are affected by chloralose anesthesia.

Since the study by Talman et al. (3) several lines of evidence have indicated the excitatory amino acid L-glutamate as the putative neurotransmitter of the baroreceptor afferents in the NTS. Despite the controversial data reported by Leone and Gordon (12) and Talman (13) with respect to the absence of blockade of the cardiovascular responses to exogenous L-glutamate after microinjection of kynurenic acid into the NTS, and the pressor response produced by L-glutamate microinjected into the NTS of unanesthetized rats reported by Machado and Bonagamba (8), several studies support the concept that L-glutamate is the putative neurotransmitter of the baroreflex at the NTS level $(1-3,6)$. In this respect, the study by Le Galloudec et al. (14) documented that the hypotensive response to L-glutamate microinjected into the NTS was effectively blocked by previous microinjection of kynurenic acid. The neurotransmission of the chemoreflex (15-18) and the Bezold-Jarisch reflex (1922 ) in the NTS also involves L-glutamate and EAA receptors. An important aspect of the neurotransmission of the different cardiovascular reflexes in the NTS is related to the subtypes of EAA receptors involved in the processing of afferent information. The cardiovagal component of the baroreflex (23), chemoreflex (16) and the Bezold-Jarisch reflex (19) as well as the bradycardic response to L-glutamate microinjected into the NTS of unanesthetized rats (24) are mediated by NMDA receptors since bilateral microinjection of AP-5, a selective NMDA receptor antagonist, produced a dose-dependent blockade of the bradycardic response to the activation of the reflexes or to the microinjection of L-glutamate into the NTS.

Studies by DiMicco and Monroe (25)
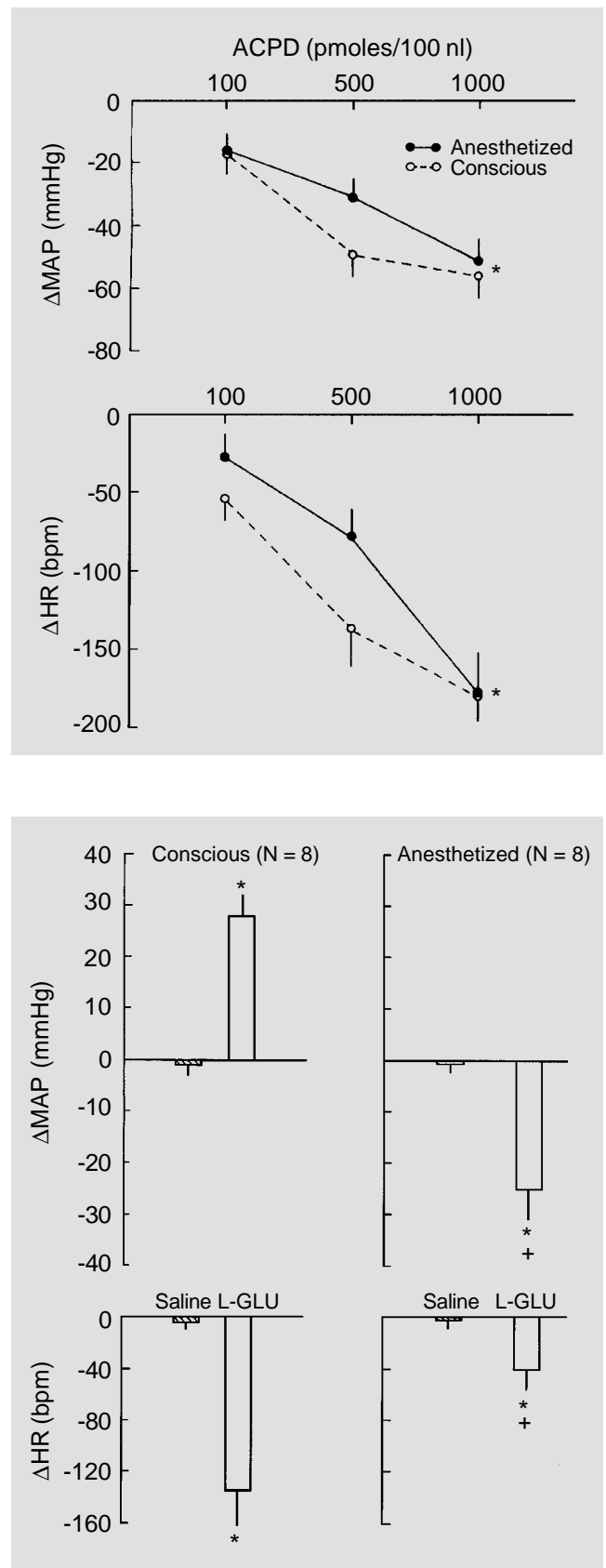

Figure 3 - Dose-dependent changes in mean arterial pressure ( $\triangle \mathrm{MAP}$, upper panel) and heart rate $(\Delta \mathrm{HR}$, bottom panel) in response to increasing doses of trans-( \pm )-1-amino-1,3-cyclopentanedicarboxylic acid (ACPD 100,500 and $1000 \mathrm{pmol} / 100 \mathrm{nl}$ ) microinjected into the NTS of the same rats $(\mathrm{N}=8)$ under conscious (broken line) and anesthetized conditions (full line). Asterisks indicate that trans-( \pm )-ACPD produced a dose-dependent reduction in MAP and HR in conscious and anesthetized rats (ANOVA, $P<0.05$ ). The changes in MAP and HR produced by each dose of ACPD into the NTS of conscious or anesthetized rats were not statistically different $\left({ }^{*} \mathrm{P}<0.05\right.$, paired $t$-test).

Figure 4 - Changes in mean arterial pressure ( $\triangle \mathrm{MAP}$, upper left panel) and heart rate $(\Delta \mathrm{HR}$, bottom left panel) in response to microinjections of saline $(100 \mathrm{nl})$ and L-glutamate (L-GLU; $1 \mathrm{nmol} /$ $100 \mathrm{nl}$ ) into the NTS of conscious rats $(\mathrm{N}=8)$ and changes in MAP (upper right panel) and HR (bottom right panel) in response to microinjections of saline $(100 \mathrm{nl})$ and L-GLU (1 nmol/ $100 \mathrm{nl}$ ) into the NTS of the same group of rats under chloralose anesthesia. ${ }^{*} \mathrm{P}<0.05$ compared to saline microinjection (paired $t$ test). $+\mathrm{P}<0.05$ compared to the response obtained under conscious conditions (paired $t$-test). 
Figure 5 - Photomicrograph of a coronal section of the brain stem of one rat representative of the groups studied showing a typical unilateral microinjection site centered in the lateral portion of the commissural NTS at the leve of the rostral edge of the area postrema, approximately 0.5 $\mathrm{mm}$ rostral to the calamus scriptorius and $0.5 \mathrm{~mm}$ lateral to the midline (arrow).

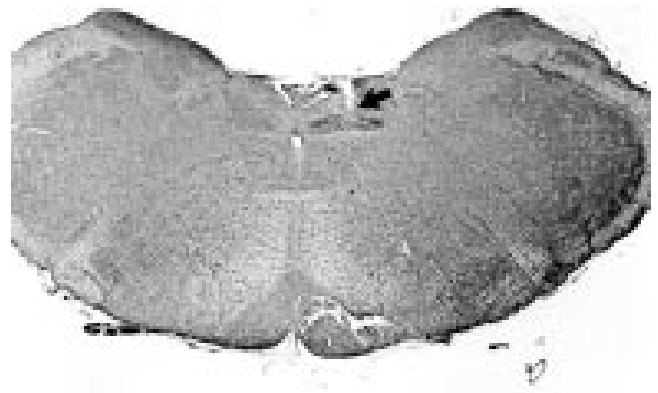

have shown that the increase in heart rate produced by microinjection of trans-(1S, 3R)ACPD into the dorsomedial hypothalamus of rats was significantly reduced by DL-2amino-5-phosphonopentanoic acid, a selective NMDA receptor antagonist, microinjected at the same area. The present data showing that microinjection of trans-( \pm ACPD into the NTS produces bradycardic responses raise an important question related to a possible interaction between metabotropic and NMDA receptors in the processing of the parasympathetic branch of the baroreflex at the NTS level because, as mentioned previously, we were able to block the bradycardic response to L-glutamate microinjected into the NTS with AP-5, a selective NMDA receptor antagonist. To answer this important question about a possible interaction between metabotropic and NMDA receptors in the processing of the parasympathetic component of the reflexes in the NTS, additional experiments involving the activation of the baroreflex in the presence of metabotropic receptor antagonists in the NTS and the activation of metabotropic receptor in the presence of NMDA receptor antagonists in the NTS are required.

In a recent study from our laboratory (6) we demonstrated that the pressor and bradycardic responses elicited by microinjection of L-glutamate into the NTS in unanesthetized rats were blocked in a dose dependent manner by kynurenic acid, indicating that both responses were mediated by excitatory amino acid receptors (ionotropic). On the other hand, a previous study from our laboratory (8) showed that the pressor response to L-glutamate microinjection into the NTS of conscious rats was converted to a depressor response when the microinjection was performed in the same rat under chloralose anesthesia. These previous studies from our laboratory indicate that the pressor response to L-glutamate is mediated by ionotropic receptors and suggest that these receptors are affected by urethane and chloralose anesthesia. Therefore, it is possible that under anesthesia the receptors related to the pressor response to L-glutamate are more affected than those associated with the depressor response and consequently L-glutamate microinjected into the NTS of anesthetized rats produced only a hypotensive response. The rationale of the present study was to test whether ionotropic and metabotropic receptors were responsible for the pressor response to L-glutamate into the NTS of conscious rats and also whether the responses to the activation of both sets of receptors were affected by anesthesia, suggesting that anesthetics like chloralose may mainly affect the ionotropic receptors since they depend upon ionic channels in the membrane, while metabotropic receptors do not. The data of the present study show that the hypotensive response to the metabotropic agonist trans$( \pm)$-ACPD is not affected by $\alpha$-chloralose anesthesia. However, the relative role of this receptor class in the processing of both autonomic components of the baroreflex, i.e., sympathetic inhibition and cardiovagal excitation, requires further investigation.

\section{Acknowledgments}

The authors thank Rubens F. de Melo for the histological preparations. 


\section{References}

1. Andresen MC \& Yang M (1994). Excitatory amino acid receptors and afferent synaptic transmission in the nucleus tractus solitarius. In: Robin I \& Barraco A (Editors), Nucleus of the Solitary Tract. CRC Press, Inc., Boca Raton, 187-192.

2. Gordon FJ \& Talman WT (1992). Role of excitatory amino acids and their receptors in bulbospinal control function. In: Kunos G \& Ciriello J (Editors), Central Neural Mechanisms in Cardiovascular Regulation. Birkhäuser, Boston, 209-225.

3. Talman WT, Perrone $\mathrm{MH}$ \& Reis DJ (1980). Evidence for L-glutamate as the neurotransmitter of baroreceptor afferent nerve fibers. Science, 209: 813-815.

4. Glaum SR \& Miller RJ (1992). Metabotropic glutamate receptors mediate excitatory transmission in the nucleus of the solitary tract. Journal of Neuroscience, 12 : 2251-2258.

5. Pawloski-Dahm C \& Gordon FJ (1992). Evidence for a kynurenate-insensitive glutamate receptor in nucleus tractus solitarii. American Journal of Physiology, 262 (Heart and Circulatory Physiology, 31): $\mathrm{H} 1611-\mathrm{H} 1615$.

6. Colombari E, Bonagamba LGH \& Machado BH (1994). Mechanisms of pressor and bradycardic responses to L-glutamate microinjected into the NTS of conscious rats. American Journal of Physiology, 266 (Regulatory, Integrative and Comparative Physiology, 35): R730-R738.

7. Colombari E, Menani JV \& Talman WT (1996). Commissural NTS contributes to pressor responses to glutamate injected into the medial NTS of awake rats. American Journal of Physiology, 270 (Regulatory, Integrative and Comparative Physiology, 39): R1220-R1225.

8. Machado BH \& Bonagamba LGH (1992). Microinjection of L-glutamate into the nucleus tractus solitarii increases arterial pressure in conscious rats. Brain Research, 576: 131-138.

9. Paxinos G \& Watson C (1982). The Rat
Brain in Stereotaxic Coordinates. Academic Press, New York.

10. Michelini LC \& Bonagamba LGH (1988). Baroreceptor reflex modulation by vasopressin microinjected into the nucleus tractus solitarii of conscious rats. Hypertension, 11 (Suppl I): I-75-I-79.

11. Haibara AS, Bonagamba LGH \& Machado BH (1996). Pressor response of chemoreflex is not blocked by bilateral microinjection of ionotropic or metabotropic antagonists into the commissural NTS. Society for Neuroscience Abstracts, 22 (Part 1): 631.

12. Leone C \& Gordon FJ (1989). Is L-glutamate a neurotransmitter of baroreceptor information in the nucleus of the tractus solitarius? Journal of Pharmacology and Experimental Therapeutics, 250: 953-962.

13. Talman WT (1989). Kynurenic acid microinjected into the nucleus tractus solitarius of rat blocks the arterial baroreflex but not responses to glutamate. Neuroscience Letters, 102: 247-252.

14. Le Galloudec E, Merahi N \& Laguzzi R (1989). Cardiovascular changes induced by local application of glutamate-related drugs in the rat nucleus tractus solitarii. Brain Research, 503: 322-325.

15. Mifflin SW (1992). Arterial chemoreceptor input to nucleus tractus solitarius. American Journal of Physiology, 263 (Regulatory, Integrative and Comparative Physiology, 32): R368-R375.

16. Haibara AS, Colombari E, Chianca-Jr DA, Bonagamba LGH \& Machado BH (1995). NMDA receptors in NTS are involved in bradycardic but not in pressor response of chemoreflex, American Journal of Physiology, 269 (Heart and Circulatory Physiology, 38): $\mathrm{H} 1421-\mathrm{H} 1427$.

17. Vardhan A, Kachroo A \& Sapru HN (1992). Excitatory amino acid receptors in commissural nucleus of the NTS mediate carotid chemoreceptor responses. American Journal of Physiology, 264 (Regulatory, Integrative and Comparative Physiol- ogy, 33): R41-R50.

18. Zhang W \& Mifflin SW (1993). Excitatory amino acid receptors within NTS mediate arterial chemoreceptor reflexes in rats. American Journal of Physiology, 265 (Heart and Circulatory Physiology, 34): $\mathrm{H} 770-\mathrm{H} 773$.

19. Chianca-Jr DA \& Machado BH (1996). Microinjection of NMDA antagonist into the NTS of conscious rats blocks the BezoldJarisch reflex. Brain Research, 718: 185188.

20. Vardhan A, Kachroo A \& Sapru HN (1993). Excitatory amino acid receptors in the nucleus tractus solitarius mediate the responses to the stimulation of cardio-pulmonary vagal afferent $C$ fiber endings. Brain Research, 618: 23-31.

21. Verberne JMA \& Guyenet PG (1992) Medullary pathway of the Bezold-Jarisch reflex in the rat. American Journal of Physiology, 263 (Regulatory, Integrative and Comparative Physiology, 32): R1195R1202.

22. Wilson CG, Zhang Z \& Bonham AC (1996). Non-NMDA receptors transmit cardiopulmonary $\mathrm{C}$ fibre input in nucleus tractus solitarii in rats. Journal of Physiology, 496: 773-785.

23. Machado BH, Frigero M, Bonagamba LGH \& Okamoto $\mathrm{R}$ (1997). NMDA receptors in the NTS mediate bradycardic responses to L-glutamate microinjection or to baroreflex activation. Society for Neuroscience Abstracts, 23 (Part 1): 146.

24. Colombari E, Bonagamba LGH \& Machado BH (1997). NMDA receptor antagonist blocks the bradycardic but not the pressor response to L-glutamate microinjected into the NTS of unanesthetized rats. Brain Research, 749: 209-213.

25. DiMicco JA \& Monroe AJ (1996). Stimulation of metabotropic receptors in the dorsomedial hypothalamus elevates heart rate in rats. American Journal of Physiology, 270 (Regulatory, Integrative and Comparative Physiology, 39): R1115-R1121. 